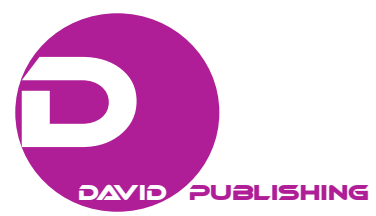

\title{
Civic and Social Applications to Support Public Policies on Health
}

\author{
Eduardo Amadeu Dutra Moresi, Michel Carmo Lopes, Júlio Cezar Alves dos Santos, \\ Marcos Augusto Alves Tito de Morais, Mário de Oliveira Braga Filho, Jair Alves Barbosa \\ Catholic University of Brasília, DF, Brazil
}

\begin{abstract}
The discussion with emphasis on social control is expressed in new guidelines for its effectiveness through normative instruments and the legal creation of institutional spaces that guarantee the participation of organized civil society in the direct supervision of the executive in the three spheres of government. Social participation for the strengthening of public health in Brazil has undergone complex processes of change, which have resulted in an increasingly qualified, deliberative, independent, and representative social control system. However, policy makers need to identify new technologies and carefully analyze their potential before they begin to exert their breaking power in the economy and society. Mobility and unlimited connectivity deserve special attention from the public power for the ability to achieve the digital inclusion of the citizen through smartphones. This requires a transformation of the governance structure into a platform that is based on the tripod transparency, participation, and collaboration, which relies on the Internet, social networks and connectivity.
\end{abstract}

Keywords: social participation, public health policies, mobile devices, civic social applications

\section{Introduction}

Popular participation in health management is provided by the Federal Constitution of 1998, Article 198, which deals with the guidelines of the Unified Health System (SUS): decentralization, integrality, and community participation. These guidelines guide the organization and operation of the system, in order to make it more adequate to meet the needs of the Brazilian population (Rolim, Cruz, \& Sampaio, 2013).

Its consolidation and regulation were recommended by the Organic Laws of Health No. 8080/90 (Brazil, 1990a) and No. 8142/90 (Brazil, 1990b), which established the guidelines and norms for the SUS, as well as

Eduardo Amadeu Dutra Moresi, Ph.D., professor, School of Education, Technology and Communication, Catholic University of Brasília, DF, Brazil.

Michel Carmo Lopes, MBA, assistant professor, School of Education, Technology and Communication, Catholic University of Brasília, DF, Brazil.

Júlio Cezar Alves dos Santos, MBA, assistant professor, School of Education, Technology and Communication, Catholic University of Brasília, DF, Brazil.

Marcos Augusto Alves Tito de Morais, MBA, assistant professor, School of Education, Technology and Communication, Catholic University of Brasília, DF, Brazil.

Mário de Oliveira Braga Filho, M.Sc., professor, School of Education, Technology and Communication, Catholic University of Brasília, DF, Brazil.

Jair Alves Barbosa, M.Sc., professor, School of Education, Technology and Communication, Catholic University of Brasília, DF, Brazil.

Correspondence concerning this article should be addressed to Eduardo Amadeu Dutra Moresi, Universidade Católica de Brasília, QS 07-Lote 01-EPCT-Bloco N-71966-700, Brasília, DF, Brazil. 
regulated their organization and functioning, criteria of transfers to states and municipalities, besides disciplining social control in accordance with the representations of the state and municipal health criteria.

The SUS brought the expansion of health care to the population, allowing a new look at actions, services, and care practices, which were guided by the principles and guidelines: universality of access to health services; completeness of assistance; equity; political and administrative decentralization; community participation; regionalization and hierarchization.

Popular participation and social control in health, among the principles of the Unified Health System (SUS), stand out as having great social and political relevance, since they constitute a guarantee that the population will participate in the process of formulating and controlling the public health policies. In Brazil, social control refers to community participation in the decision-making process on public policies and control over state action (Arantes, Mesquita, Machado, \& Ogata, 2007).

On the other hand, advances in Information and Communication Technology (ICT) should be part of a positive agenda for inclusion, increased transparency of government decisions, greater popular participation in policymaking, and thus a real increase in citizenship and social control. The advancement of cloud computing technologies, mobile devices, and social networks has shown great potential in contributing to this greater integration between government and society. All of them make great use of the possibilities of the Internet as a new arena for social participation, political activism and business. The issue of digital activism is recent and still lacks the tools to effectively promote effective action, integrating people with government decisions and the latter with the commitment to solve their problems.

However, the ordinary citizen still cannot use this data without any previous treatment that facilitates its interpretation. Civic technologies seek to fill this gap by using the Internet and mobile devices to facilitate access and interpretation of data opened by ordinary citizens. In this sense, the objective of this work is to present the use of mobile devices to stimulate social participation to strengthen public health policies. Three examples of civic social applications that have been developed in iOS are presented, employing the Challenge Based Learning (CBL) methodology (Nichols, Cator, \& Torres, 2016).

\section{Citizen Participation and Social Control}

The discussion with emphasis on social control in the new Constitution is expressed in new guidelines for its effectiveness through normative instruments and the legal creation of institutional spaces that guarantee the participation of organized civil society in the direct supervision of the executive in the three spheres of government. Thus, all citizens' rights to health are guaranteed by the Federal Constitution, which reiterates that it is the duty of the State to guarantee the right to health. In Brazil, since 1988, public health policies have been guided by the principles of universality and equity in access to actions and services and by the guidelines of decentralization of management, integral care, and community participation, in the organization of a SUS in the national territory (Rocha, 2008).

Essential for participation is the reduction of the distance between society and the manager of public policy, understanding this as something constant in everyone's life (Pêgo, as cited in Coelho, 2012, p. 145). That is, the public policies are not exclusive initiatives of the state apparatus, but fruit of interlocution and agreement between social actors with diversity of interests and needs. Therefore, communication as a dialogic process is fundamental to citizen participation and social control. Mobile devices will soon become a tool for inclusion and social participation. Therefore, it is important to ensure adequate and sufficient 
access to information produced by SUS and the right of each to express them, to be heard and considered (Coelho, 2012).

In short, the Brazilian government still faces difficulties in consolidating the practice of social participation, even though it has legally established spaces for this purpose, since the 1988 Constitution. Despite the indisputable quantitative advances observed in recent years, the consolidation of social participation in Brazil still faces numerous challenges, especially in terms of improving the quality and effectiveness of social participation spaces. In fact, many steps must be taken until, in fact, the deliberations of civil society are sent to the appropriate bins of the Federal Public Administration and are materialized in measures and public policies appropriate to the population.

\section{Mobile Devices}

The advance of technology continues to drive economic growth and, in some cases, trigger disruptive change. Economically disruptive technologies - such as semiconductor microchips, the Internet, or steam power in the Industrial Revolution - transform the way people live and work, allowing new business models and providing an opening for new actors to change the established order. Business leaders and policy makers need to identify potentially disruptive technologies and carefully analyze their potential before they begin to exert their breaking power in the economy and society. However, only a few technologies have the potential to transform reality by changing the way people live and work, redirecting the perception of value and leading to entirely new products and services.

The McKinsey Global Institute (Manyika, Chui, Bughin, Dobbs, Bisson, \& Marrs, 2013) conducted a study that outlines the 12 technologies that have a combined potential economic impact of tens of trillions of dollars per year from 2025. Trends are:

- mobile internet: increasingly cheaper mobile computing devices with higher capacities and better Internet connectivity;

- internet of things: networks of sensors and low-cost actuators for data collection, monitoring, decision-making and process optimization;

- cloud technology: use of hardware and software resources delivered through a network or the Internet, often as a service.

The power of new technologies is everywhere. Social media was virtually unknown a decade ago. Today, almost one billion people have Facebook accounts, establishing a new order in how to socialize and interact with friends, family, and colleagues. Technologies such as mobile Internet are helping to accelerate economic development by enabling millions of people in remote areas of developing regions to be included in the $21 \mathrm{st}$ century global economy.

Gartner (Dreyfuss, 2014) has identified four converging forces that will impact organizations and their relationship to their external environment. The forces are: cloud computing, which leads organizations to rethink their IT infrastructure investments due to decreasing costs to meet their needs; social, which allows a much broader and deeper involvement of citizens in their relationship with government agencies; information, which assumes a prominent role in any organization, with data in various formats and from different sources, offering more opportunities for more accurate analysis and more informed decisions; mobile, with the explosion of devices (smartphones and tablets) as the main means of access to information and social interaction. 
Mobility and the unlimited connectivity of people with the surrounding world through mobile devices is already a reality and the growth of this trend is one of the main bets of companies focused on the future. With the advent of smartphones and the development of a wide variety of applications, people have come to enjoy an explosion of connections. Never before have individuals been so connected to other people, environments, businesses, and objects.

Today, interaction is frequent and organizations already understand the potential of this change and invest in the development of new sources of value. It is possible to perceive the presence of new technologies in the creation of new business models and services online, in the growing generation of information in real time, in the effective identification of users when accessing systems and equipment, in the global management of operations, in the refinement of intelligent operations, the innovative offering of cloud computing, the expansive use of social networks, and the care for protection and privacy while exchanging all of these interconnected data.

In a few years, Internet-enabled mobile devices will move from a luxury to few to a way of life for more than a billion people who have smartphones and tablets (Manyika et al., 2013). The ubiquitous connectivity and explosive proliferation of applications are allowing users to adapt their daily routines to new ways of knowing, perceiving, and even interacting with the real world. Mobile Internet technology is evolving rapidly, with intuitive interfaces and new formats, including handheld devices. Mobile Internet also has applications for businesses and the public sector, enabling more efficient delivery of many services and creating opportunities to increase workforce productivity.

Access to government data enables the creation of applications that promote social control and citizen participation, as well as creating conditions for the improvement of public policies and services. There is a transformation of the governance structure into a platform that is based on the tripod transparency, participation, and collaboration, and relies on Internet technologies, especially on social networks and mobile device connectivity (O'Reilly, 2011). The emergence of civic applications enables the creation of a layer that adds value to the open government data, allowing the application of a business model approach, further enhancing the possibilities of interaction with society (Albano, 2014; Germano, 2013).

Bimber (2000) highlights the possibilities of the strong relationship between technology and citizenship, emphasizing that especially the younger ones feel comfortable with the political debate in the digital format. The author stresses that discussion should not be limited to naming specific technologies as a source of civic engagement, but rather to highlight the flow of information as a transformer, whether flowing through the Internet, the television system, radio, mobile applications, or other emerging technology. Another interesting aspect is that more and more technologies tend to integrate, and thus their boundaries of distinction will become more difficult, keeping the debate about the flow of information itself and its potential.

As the development of these applications is still in an initial state, there is still a lot of room for improvement in Brazil's open data infrastructure. Brito, Costa, Garcia, and Meira (2015) mention some aspects that should be observed: the number of public bases which is still low; the need to keep the data up to date; removal of the need to register or obtain a license; standardization of data; the creation of return channels that allow interaction with the citizen.

However, only the publication of data by governments does not guarantee citizen participation. New technologies can bring about significant changes in societies, particularly when the citizen becomes the protagonist through his active participation in the process of transformation of society. The possibility of 
questioning the quality of public services or evaluating public policies, guarantees the citizen's role. Technology represents new ways of doing things, and once mastered, it creates a lasting change that organizations and people do not "unlearn".

\section{Methodology}

The methodology followed for application development comprised the following steps:

- bibliographic research: Studies and bibliographical surveys were carried out to the knowledge of the state of the art of the proposed theme, being carried out consultations to the bases of the CAPES Portal and to the Brazilian Digital Library of Theses and Dissertations, besides the reference documents on the Unique System of Cheers;

- definition of the application scope: use of the Challenge Based Learning (CBL) method to define the scope of the application. At this stage, the key actors were identified to achieve the proposed objectives, in addition to face-to-face interactions for needs assessments and requirements for application development;

- application development using Scrum (Priklandnicki, Willi, \& Milani, 2014);

- testing and publishing: The developed application was tested for 30 days. After the suggestions adjustments were received, the application was published to the Apple Store.

\section{The Health Map Application}

The Health Map is an application developed for the iOS platform, whose main objective is to provide useful information to the citizen about the health institutions registered in the CNES (National Register of Health Establishments), which is maintained by the Ministry of Health Datasus of the information query; the application allows the citizen to evaluate the health establishment and report on incorrect data found in the CNES register.

In the application of the CBL method the great idea was identified: to develop an application with information useful to the citizen about Brazilian health facilities, indication of routes of access from the current location of the user to the desired organization, and dynamic searches depending on the service area doctor.

The above issues were submitted to two public health experts, a Datasus technician, two designers, and two developers for the iOS platform. The synthesis of the answers allowed identifying the challenge of developing the Health Map with the following functionalities: to visualize the establishments closest to the user; to search for the name of the establishment, medical specialties, or category of health institutions; to interact with information from health facilities, such as making calls, sending e-mails, conducting evaluations, adding favorite establishments for easy access, among others; to navigate assistant to the chosen facility; to access to the list of professionals, specialties, and services of the establishment; report of problems regarding the information presented by the institution, and the user can suggest corrections; evaluation of the health establishment.

Figure 1 shows some screens of the application. The first screen allows you to identify health facilities close to the user's location. When choosing an establishment, you can have access to your complete information, as shown on the second screen. The following screen shows the evaluation categories for each health establishment. In order to perform the evaluation, the user must be registered in the application. This was a suggestion from public health experts seeking to avoid non-relevant information. The evaluation comprises the following attributes: general evaluation; waiting time; availability of physicians; infrastructure; medicines 
and products; equipment and beds; accessibility. The last screen displays the specialty search functionality. The result shows the establishments closest to the user's current location. It should be noted that the application has other screens that are useful to the user. One is the navigation map that allows you to trace a route between the user's current location and the health facility of interest.

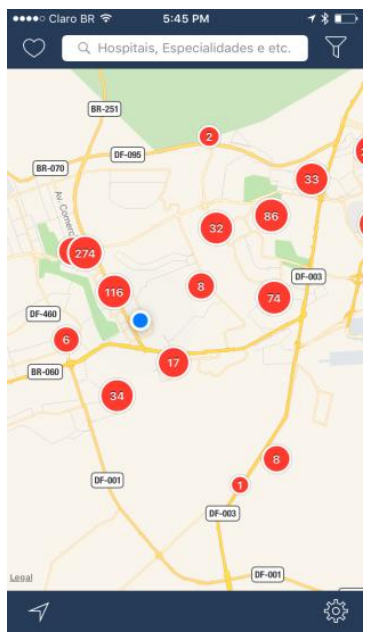

(a)

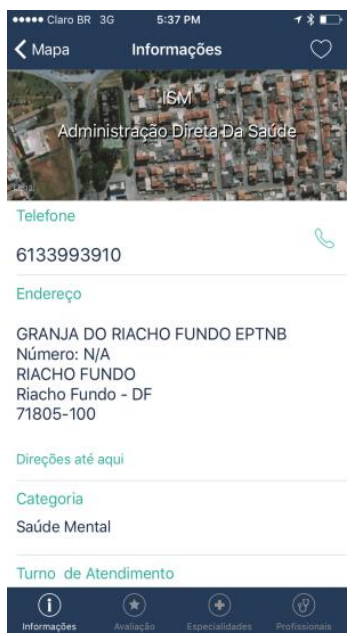

(b)

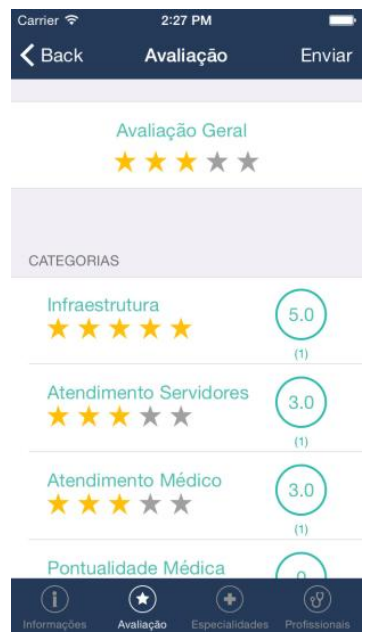

(c)

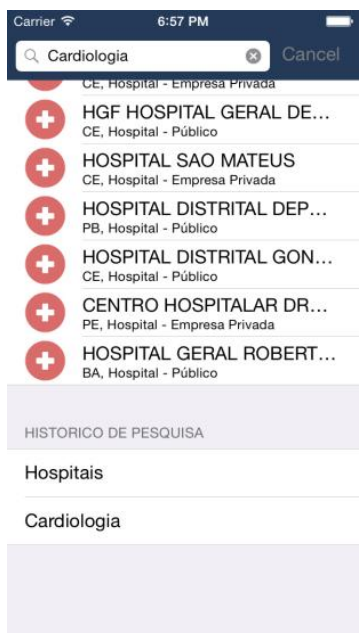

(d)

Figure 1. App Screens Health Map: (a) home screen, (b) health facility information, (c) evaluation, (d) research on specialties.

The Health Map is available for free download in the App Store in Version 1.3.4, being compatible with iPhone, iPad, iPod, and Apple Watch, in Portuguese and English. The application is being used by more than 5,000 people in Brazil and more than 300 countries like: United States, Japan, Portugal, and Dominican Republic. Information is available on more than 270,000 registered health institutions in CNES, covering the entire country.

The conceptual approach to application development highlights the importance of mobility and connectivity in generating ideas for solving everyday problems. Yet only ideas are not enough to reach the solution. They must be implemented in products or services that meet the needs of society.

The Health Map application presents the following relevant points:

- first App published with information from all health facilities registered at CNES;

- covers all health facilities in Brazil;

- establishes a channel of communication with citizens, allowing them to participate in the evaluation of public health policies;

- allows the reporting of problems on the information registered and published in CNES by Datasus;

- is available in English and Portuguese, which facilitates use by foreigners;

- was conceived as a service that allows the citizen to interact with the public power.

\section{The VacinApp Application}

VacinApp was developed for the iOS platform, whose main objective is to offer an application that allows managing multiple vaccination cards. In the application of the CBL method the great idea was identified: to develop an application that registers and controls the vaccines of the whole family. To identify the challenge, the following key question was raised: How to manage vaccination cards digitally, alert the immunization campaigns in your region and the location of vaccination posts? 
From the answer to these questions the following challenge was defined: to create an application that can manage multiple profiles of vaccines cards, using geolocation for the identification of health posts. The development team counted on the guidance of public health experts who indicated bibliographies of support (Brazil, 2014; 2016).

VacinApp is an application for the Brazilian population with the purpose of facilitating the visualization of the user's vaccination card, as well as identifying the nearest Vaccination Centers where a vaccine can be taken. People who need to better organize their vaccines and stay informed about vaccination campaigns in their region will realize the usefulness of the application. Table 1 presents the main features of the application and their respective descriptions.

Table 1

VacinApp Features

\begin{tabular}{|l|l|}
\hline Functionality & Description \\
\hline View the vaccination card & The vaccination card is organized and modularized by age, profile, and user needs. \\
\hline Manage family cards & It manages the user profiles by cart, through a simple menu that allows the familiar control. \\
\hline Modify the vaccination card & You can add new vaccines to your chart, delete existing records, and change expiration dates. \\
\hline Export vaccination card & You can export the carton to the iCloud cloud, in pdf, by e-mail (jpeg). \\
\hline View map of health posts & $\begin{array}{l}\text { A map containing all vaccination posts in Brazil can be chosen and navigated. The presentation } \\
\text { always starts with the user's current location. }\end{array}$ \\
\hline Publish campaign reminders & $\begin{array}{l}\text { There is a welcome screen containing reminders of vaccination campaigns and locations they } \\
\text { are currently experiencing. }\end{array}$ \\
\hline
\end{tabular}

VacinApp's main screen presents the user with a map and the current user location and the nearest health centers, as shown in Figure 2. The lower navigation bar has the following options: map, vaccination card, recent feedbacks, and settings. As soon as the user enters, a login screen is shown. The logon process can be done by registering or by using a social media account with Facebook and Twitter. The app enables the evaluation of health centers and vaccination points. The two last screens consist of the latest evaluations, and the review notes for each evaluation. The facial expression of the icon reflects if the evaluation is positive or negative. This feature is interesting, as it makes the explicit opinion of the community regarding the vaccination centers. Mainly informal registries, health secretariats can use this information to rank and evaluate the services provided by the center.

Before this publication, public health experts, auditors from the Tribunal de Contas da União (TCU) and users have reviewed the application. The suggestions were blended into the new version of the app. VaccinApp is available as a free download on the App Store, on the 1.1 version, compatible to iPhone, iPad, and iPod Touch.

The conceptual approach to application development underscores the importance of mobile devices in transforming ideas into innovative products or services. The problem to be solved by VacinApp is aimed at the loss of vaccination cards, the difficulty of finding vaccination posts, and the dissemination of immunization campaigns. At the time of application development, many adults were consulted about the vaccine card, most of whom replied that they did not have the document. Others said they were unaware of the vaccines they should take and the timing of immunization. Therefore, the relevant points of the application are: management of multiple profiles, including dependents; identification of the nearest vaccination posts; possibility of exporting each vaccine card; information on community opinion on vaccination posts; information about immunization vaccines. 


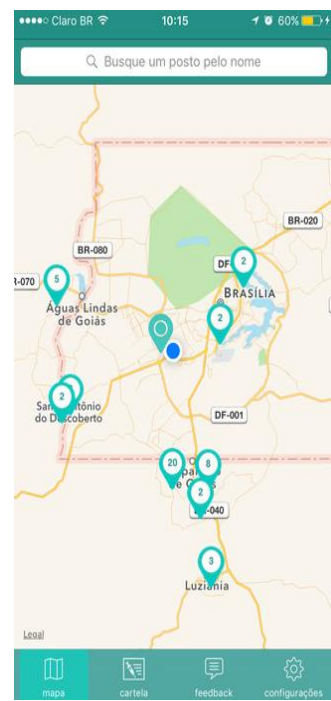

(a)

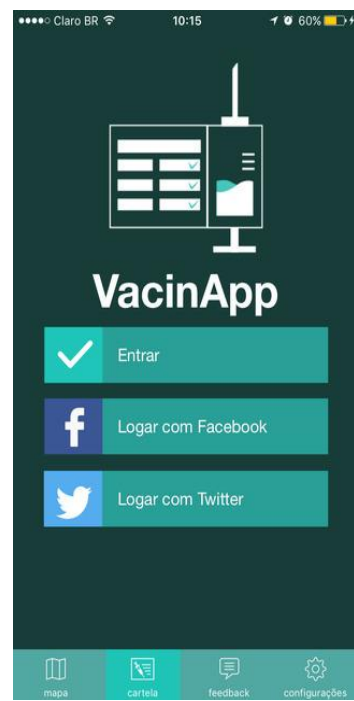

(b)

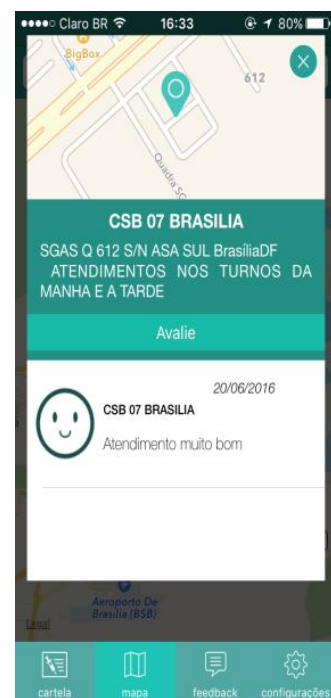

(c)

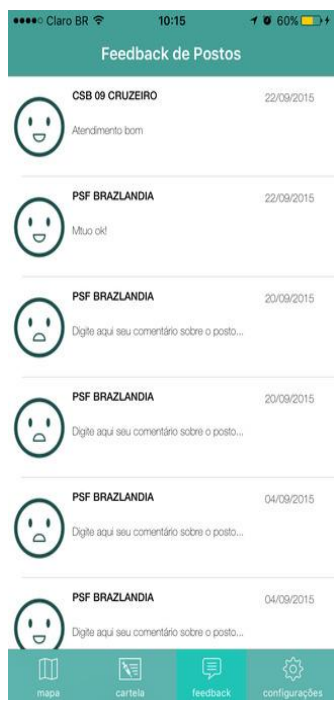

(d)

Figure 2. App VacinApp screens: (a) home screen, (b) login to the application, (c) evaluation of the Vaccination Point, (d) shared opinions about care at the Vaccination Posts.

\section{Conclusion}

The objective of this article was to present the use of mobile devices to stimulate social participation for the strengthening of public health policies. Initially, aspects were discussed in the legislation creating the Unified Health System emphasizing the importance of popular participation and social control in health, which stand out for creating conditions for the population to participate in the process of formulation and control of public health policies. Institutional channels of co-management with the state have also been created, which have brought about significant changes in political power relations and the distribution of responsibilities between the state and society, and between the three spheres of government-federal, state, and municipal.

However, citizen participation and social control presume the reduction of the distance between society and the manager of public policy. Public policies are not exclusive initiatives of the state apparatus, but fruit of interlocution and agreement among social actors with diversity of interests and needs. The shortening of this distance is still a great challenge.

The digital inclusion of citizens through mobile devices begins to gain notoriety. The article explores the potential of mobile devices as a means of social inclusion and of stimulating citizen participation. The mobility and unlimited connectivity of people, through smartphones, has transformed the reality of society and consolidated the growth of this trend, being one of the main bets for the future.

Smartphones and the development of a wide variety of applications have resulted in an explosion of connections, in which individuals are now connected to other people, environments, businesses, and objects. Exploring this trend of mobility and connectivity with the development of civic applications should be the most viable alternative to strengthen social control and participation.

Therefore, access to open government data by civic applications that transform them into intelligible information for ordinary citizens opens up a new perspective by creating conditions for improving public policies and services. It is expected that there will be a transformation of the governance structure into a technological platform that is based on the tripod transparency, participation, and collaboration, mainly in the social networks and the connectivity of the mobile devices. 


\section{References}

Albano, C. S. (2014). Dados governamentais abertos: Proposta de um modelo de produção e utilização de informações sob a ótica conceitual da cadeia de valor. São Paulo: Universidade de São Paulo.

Arantes, C. I. S., Mesquita, C. C., Machado, M. L. T., \& Ogata, M. N. (2007). O controle social no Sistema Único de Saúde: Concepções e ações de enfermeiras da atenção básica. Texto \& Contexto Enfermagem, 16(3), 470-478.

Bimber, B. (2000). The study of information technology and civic engagement. Political Communication, 17(4), $329-333$.

Brazil. (1990a) Lei $n r$ 8.142, de 18/12/1990: Dispõe sobre as condições para a promoção, proteção e recuperação da saúde, a organização e o funcionamento dos serviços correspondentes e dá outras providências. Brasília: Congresso Nacional.

Brazil. (1990b). Lei nr 8.080, de 19/09/1990: Dispõe sobre a participação da comunidade na gestão do Sistema Único de Saúde (SUS) e sobre as transferências intergovernamentais de recursos financeiros na área da saúde e dá outras providências. Brasília: Congresso Nacional.

Brazil. Ministério da Saúde. (2014). Para entender o Controle Social na Saúde. Ministério da Saúde, Conselho Nacional de Saúde. Brasília: Ministério da Saúde.

Brazil. Ministério da Saúde. (2016). Calendário Nacional de Vacina. Retrieved from http://portalsaude.saude.gov.br/index.php/o-ministerio/principal/leia-mais-o-ministerio/197-secretaria-svs/13600-calendarionacional-de-vacinacao (access on 24-05-2016)

Brito, K. S., Costa, M. A. S., Garcia, V. C., \& Meira, S. R. L. (2015). Is Brazilian open government data actually open data?: An analysis of the current scenario. International Journal of E-Planning Research, 4(2), 57-73.

Coelho, J. S. (2012). Construindo a Participação Social no SUS: Um constante repensar em busca de equidade e transformação. Saúde Soc. São Paulo, 21(supl. 1), 138-151.

Dreyfuss, C. (2014). Nexus of forces, 2014: Unleashing the power of digitalization. Retrieved from http://www.afsug.com/library/documents/saphila2014_presentations/Day1/BALLROOM_A/Nexus\%20of\%20Forces,\%2020 14\%20Unleashing\%20the\%20Power\%20of\%20Digitalization\%20-\%20Cassio\%20Dreyfuss.pdf (access on 08-07-2015)

Germano, E. C. (2013). Modelos de negócios adotados para o uso de dados governamentais abertos: Estudo exploratório de prestadores de serviços na cadeia de valor dos dados governamentais abertos. São Paulo: Universidade de São Paulo.

Manyika, J., Chui, M., Bughin, J., Dobbs, R., Bisson, P., \& Marrs, A. (2013). Disruptive technologies: Advances that will transform life, business, and the global economy. NY: McKinsey Global Institute.

Nichols, M., Cator, K., \& Torres, M. (2016). Challenge based learner user guide. Redwood City, CA: Digital Promise.

O'Reilly, T. (2011). Government as a platform. Innovations: Technology, Governance, Globalization, 6(1), 13-40.

Priklandnicki, R., Willi, R., \& Milani, F. (2014). Métodos ágeis para desenvolvimento de software. Porto Alegre: Bookman.

Rocha, E. (2008). A Constituição Cidadã e a institucionalização dos espaços de participação social: Avanços e desafios. In Associação nacional dos auditores fiscais da receita federal do Brasil-ANFIP. 20 anos da Constituição Cidadã: avaliação e desafios da Seguridade Social. Brasília: ANFIP.

Rolim, L. B., Cruz, R. S. B. L. C., \& Sampaio, K. J. A. J. (2013). Participação popular e o controle social como diretriz do SUS: Uma revisão narrativa. Saúde em Debate, 37(96), 139-147. 